\title{
Evaluation of Destaining Property of Denture Cleansers on Heat-cured Denture Base Resins using Common Indian Food Stains
}

\author{
${ }^{1}$ Sandhya Gopalakrishnan, ${ }^{2}$ KR Kashinath, ${ }^{3}$ Philip Mathew
}

\begin{abstract}
Aim: To compare the efficacy of two different denture cleansers in removing tea and paan stains from conventional and highimpact heat-cured denture base resins and also to find out the duration of contact required by the dentures with cleansers, for best results.
\end{abstract}

\begin{abstract}
Materials and methods: A total of 80 specimens ( 40 conventional and 40 high impact) were fabricated. The samples were stained with tea and paan solutions. Stained samples were subjected to immersion in denture cleansers, namely Dentural (sodium hypochlorite) and Fitty Dent (sodium perborate). Optical density values were measured using spectrophotometer at prestain, poststain, postcleansing 15 minutes, postcleansing 8 hours, and post cleansing brushing. The data were analyzed statistically.
\end{abstract}

Results: High-impact denture base resins stained more than the conventional denture base resin. Staining potential of paan solution was higher than that of tea solution. Dentural (sodium hypochlorite) is superior to Fitty Dent (sodium perborate) in the removal of stains at postcleaning 15 minutes and 8 hours immersion time in both the denture bases and 8 hours immersion time is better.

Conclusion: Both cleansers were effective in removing stains from denture surface, and Dentural is a better cleanser than Fitty Dent for all the postcleansing stages.

Clinical significance: Adequate removal of extrinsic stains from denture surface is essential for the health of the supportive area. The clinician must suggest an acceptable cleansing regime to the patient.

Keywords: Denture, Denture base resins, Denture cleansers, Paan stain, Spectrophotometer, Tea stain.

How to cite this article: Gopalakrishnan S, Kashinath KR, Mathew P. Evaluation of Destaining Property of Denture Cleansers on Heat-cured Denture Base Resins using Common Indian Food Stains. Int J Prosthodont Restor Dent 2017;7(2):53-59.

\footnotetext{
${ }^{1,3}$ Assistant Professor, ${ }^{2}$ Principal, Professor and Head

${ }^{1}$ Department of Prosthodontics, Government Dental College Kottayam, Kerala, India

${ }^{2}$ Department of Prosthodontics, Sri Siddhartha Dental College Tumkur, Karnataka, India

${ }^{3}$ Department of Community Medicine, Pushpagiri Institute of Medical Sciences \& Research Center, Thiruvalla, Kerala, India

Corresponding Author: Sandhya Gopalakrishnan, Assistant Professor, Department of Prosthodontics, Government Dental College, Kottayam, Kerala, India, Phone: +919446286788 e-mail: sandhya_gopal@rediffmail.com
}

Source of support: Nil

Conflict of interest: None

\section{INTRODUCTION}

Removable acrylic dentures help to replace missing natural teeth and their associated structures. The denture base, as well as the teeth, is fabricated using poly(methyl methacrylate) (PMMA) resin. The need to clean dentures on a regular basis is due to the inherent property of acrylic resin to attract stains and odor-producing organic and inorganic deposits. ${ }^{1,2}$ Adequate cleaning of the dentures is necessary for the health of the supportive area, and the clinician must suggest a good maintenance regime for the same.

Stains of betel and tobacco (paan chewing); beverages like tea, coffee, and cola; and turmeric (common ingredient of Indian food) along with bacterial plaque accumulate on the dentures of an average Indian patient due to the diverse food habit. A continued neglect of home care and lack of suitable cleansing result in accumulation of these undesirable substances on the surface of dentures, which contributes as one of the factors responsible for producing bad odor and adverse tissue response., ${ }^{3,4}$ The American Dental Association ${ }^{5}$ has recommended the use of hand soap and a properly designed denture brush for cleaning an adequately polished denture. This regime may not always be effective in geriatric patients due to their reduced manual dexterity. The use of chemical denture cleanser soaks is the second most popular method of denture cleansing. They are available as alkaline peroxides, alkaline hypochlorite, dilute organic or inorganic acids, disinfectants, and enzymes. ${ }^{6}$

An ideal denture cleanser should effectively remove deposits (organic and inorganic) and stains from the denture surface. They also have an important role in disinfection of denture which can reduce the incidence of denture stomatitis.

In Indian market, various formulations are available for purchase as over-the-counter products, and their compositions are not completely disclosed. Therefore, there is a need to identify the ideal cleanser for the benefit of the denture wearer.

The present study has been undertaken to find out the relative efficacy of two different denture cleansers 
in removing the tea and paan stains from two different heat-cured acrylic resin specimens. Also, we wanted to find out the duration of contact required by the dentures with commercially available cleansers, for the best results.

\section{MATERIALS AND METHODS}

The in vitro study was done at a dental college in South India. Two types of denture base materials (DPI conventional, DPI high impact) were selected for the study (Fig. 1A). A total of 80 specimens (40 conventional and 40 high impact) were fabricated. The samples of acrylic resin strips were prepared using modeling wax for the wax patterns, so as to fit into the cuvette or specimencarrying chamber of the spectrophotometer (Fig. 1D). These wax patterns were flasked in dental flasks with dental plaster and dental stone. After wax elimination, packing was done with heat-cured acrylic resin, and after trial closure, the final closure was done. They were then bench-cured for 30 minutes and then subjected to a short curing cycle of 1.5 hours. The samples were then deflasked, trimmed, and polished using progressive grits of sandpaper, finally ensuring that the dimensions of $20 \times$ $10 \times 2 \mathrm{~mm}$ were maintained (Fig. 1E). After finishing and polishing, the samples were stored in distilled water for 24 hours so as to reduce the residual monomer present.
Then the baseline optical density of each of the unstained samples was determined for future comparison and to eliminate the samples with porosities.

The tea solution was prepared by dissolving commercially available tea leaves in $500 \mathrm{~mL}$ of boiling water and leaving it for 2 minutes. Solution was filtered in muslin cloth and cooled. The paan solution was prepared by blending betel leaves, betel nuts, tobacco, lime, and water and then straining the resultant mixture (Fig. 1C). The lambda $\max (\lambda \max )$, i.e., the wavelength at which the spectrophotometer [ultraviolet-visible (UV-VIS)] light is sensitive to each specific staining media, was determined.

The polished acrylic specimens were treated with fresh human unstimulated saliva for 2 minutes to form initial pellicle layer to facilitate uptake of stain. Out of 40 conventional heat-cured specimens, 20 specimens were soaked in tea solution and the other 20 in paan solution. The optical density was measured. The same method was followed for high-impact heat-cured specimens.

Two commercially available and widely popular dental cleansers were selected for the study (Fig. 1B). Alkaline hypochlorite (Dentural) selected for the study contains sodium hypochlorite $(1.5 \% \mathrm{w} / \mathrm{v}$ available chlorine), while the alkaline peroxide (Fitty Dent) contains sodium perborate. Out of 20 specimens (conventional)
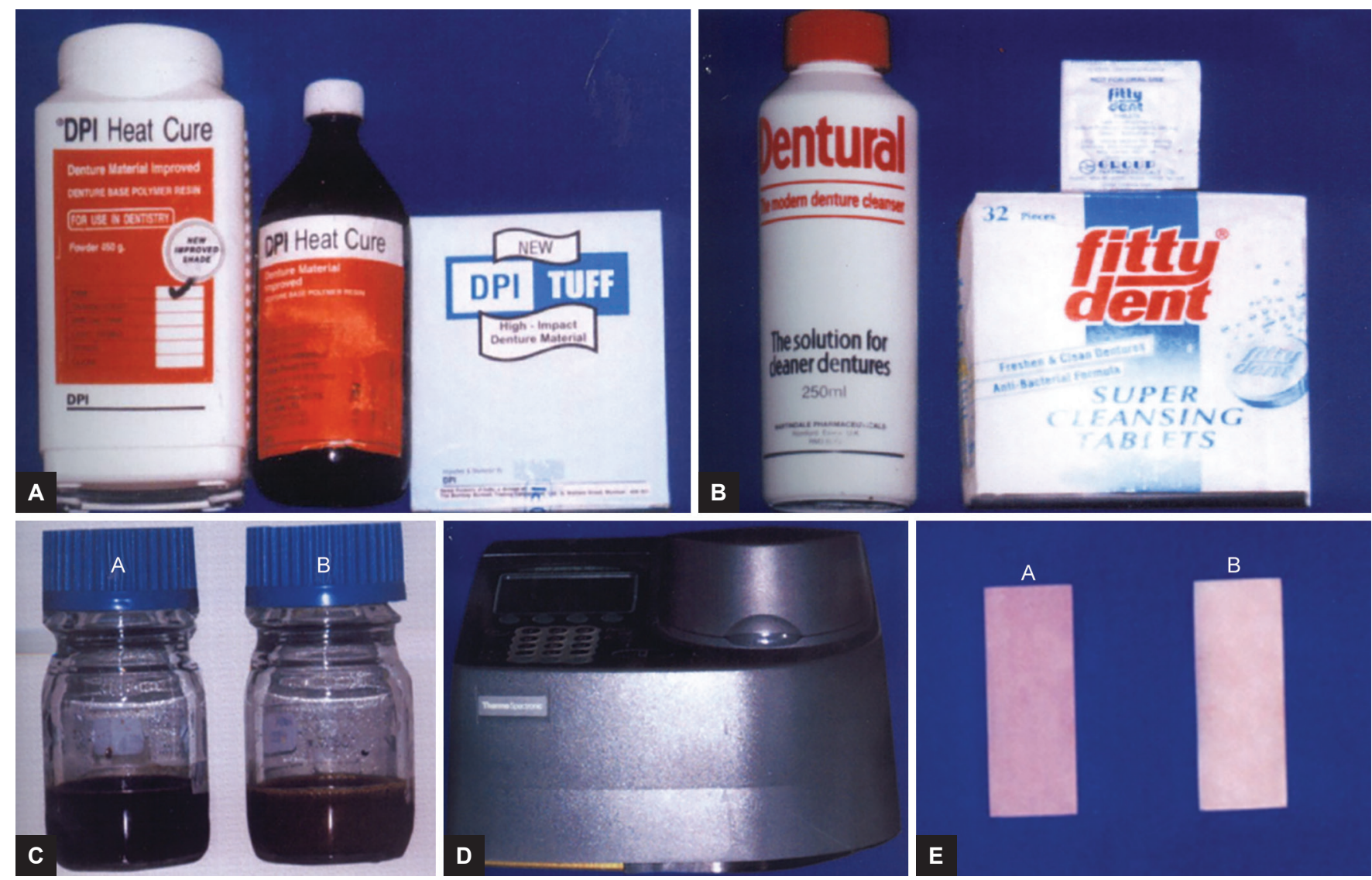

Figs $1 \mathrm{~A}$ to $\mathrm{E}$ : Materials used in the study. (A) Denture base resins; (B) cleansers; (C) staining solutions (a, tea solution and b, paan solution); (D) spectrophotometer; and (E) specimens (a, conventional and b, high impact) 
that were soaked in tea solution, 10 specimens were soaked in the slurry solution of Fitty Dent and other 10 in Dentural and the optical density measured with spectrophotometer at the end of 15 minutes (so as to simulate in between meals immersion), at the end of 8 hours (simulating overnight immersion), and also after brushing. They were then removed, allowed to dry, and evaluated for the efficacy of stain removal of the denture cleanser, by measuring the optical density (at the various corresponding $\lambda$ max of each stain) of the treated specimens by using a spectrophotometer. This process was repeated for the various stains separately and the mean values obtained. The values obtained were statistically analyzed using Statistical Package for the Social Sciences software version 13.0. Mean and standard deviations were estimated from the samples for each stain groups (baseline reading). The values obtained were then statistically analyzed using Student's t-test. In the above test, p-value $<0.05$ was accepted as indicating statistical significance.

\section{RESULTS}

An in vitro study was conducted to evaluate the destaining capabilities of two denture cleansers with different chemical compositions. The efficacy of these cleansers was investigated on two commercially available heatcured denture base resins.

The efficacy of stain removal of the denture cleanser was found out by measuring the optical density (at the various corresponding $\lambda$ max of each stain) of the treated specimen by using a spectrophotometer. Initially, the optical densities were measured without subjecting the dentures to stains. This was done to find out the baseline optical densities for record and future comparisons. The optical densities were measured in the prestaining period, poststaining period, postcleansing 15 minutes, postcleansing 8 hours, and after brushing. It was found that the mean optical densities were statistically different from each other, between conventional and high-impact resins, in all the measurements made at baseline (Table 1).
The optical densities were again measured following staining the dentures with tea solution and paan solution. The measurements were made after subjecting them to the two commercially available cleansing solutions. Again, optical densities were measured during prestaining period, poststaining period, postcleansing 15 minutes period, postcleansing 8 hours, and after brushing. When measurements were made for conventional dentures, it was found that the optical densities were significantly higher in case of cleansing with Dentural at postcleansing 15 minutes and 8 hours, after staining with tea solution. Also, it was found that the optical densities were significantly higher in case of cleansing with Dentural at postcleansing 15 minutes and 8 hours, after staining with paan solution (Table 2).

When measurements were made for high-impact dentures, it was found that the optical densities were significantly higher in case of cleansing with Dentural at postcleansing 15 minutes and 8 hours, after staining with tea solution. Further, the optical densities were significantly higher in case of cleansing with Dentural at postcleansing 15 minutes and 8 hours, after staining with paan solution (Table 3).

A comparison of both the dental cleansers was made for 8 hours cleansing and postbrushing stages. The comparison was made following staining of both types of denture bases with tea solution and paan solution. It was found that the optical densities were comparable in all the groups, and no significant changes were observed as per the type of dental cleanser or the type of stain (Table 4).

\section{DISCUSSION}

Poly(methyl methacrylate) resin used for the fabrication of removable partial and complete dentures attracts stains and odor-producing organic and inorganic deposits. Plaque is responsible for halitosis and mucosal inflammation in many denture wearers. ${ }^{7}$ The use of teeth with more natural contours and the trend toward stippled surfaces tend to provide more recessed areas for the accumulation of stains and debris and, consequently, increase the patients' cleaning problems. ${ }^{8}$ Deposits that form on the

Table 1: Optical density of the denture bases at baseline

\begin{tabular}{lllll}
\hline Time of measurement & Type of denture base & Mean optical density $(\lambda$ max) & Standard deviation $(S D)$ & $p$-value \\
\hline Pre-stain & Conventional & 1.05240 & .00573 & 0.000 \\
& High Impact & 1.01490 & .02859 & 0.019 \\
Post-stain & Conventional & 1.25648 & .02103 & .00992 \\
& High Impact & 1.26532 & .01302 & 0.000 \\
Post-cleansing & Conventional & 1.15097 & .02347 & 0.000 \\
15 minutes & High Impact & 1.16925 & .00993 & .01550 \\
Post-cleansing & Conventional & 1.12450 & .01799 & 0.001 \\
8 hours & High Impact & 1.13975 & .01539 & 0 \\
Post-cleansing & Conventional & 1.12570 & 1.13857 & \\
brushing & High Impact & &
\end{tabular}


Table 2: Optical density following staining and cleansing in conventional denture bases

\begin{tabular}{|c|c|c|c|c|c|}
\hline Type of stain & Time of measurement & Denture cleanser & Mean optical density $(\lambda \max )$ & Standard deviation (SD) & $p$-value \\
\hline \multirow[t]{8}{*}{ Tea } & \multirow[t]{2}{*}{ Pre-stain } & Dentural & 1.05140 & .00357 & \multirow[t]{2}{*}{.512} \\
\hline & & Fitty Dent & 1.04970 & .00713 & \\
\hline & \multirow[t]{2}{*}{ Post-stain } & Dentural & 1.26010 & .00856 & \multirow[t]{2}{*}{.497} \\
\hline & & Fitty Dent & 1.25760 & .00752 & \\
\hline & \multirow{2}{*}{$\begin{array}{l}\text { Post-Cleansing } \\
15 \text { minutes }\end{array}$} & Dentural & 1.16640 & .01090 & \multirow[t]{2}{*}{.000} \\
\hline & & Fitty Dent & 1.14420 & .00503 & \\
\hline & \multirow{2}{*}{$\begin{array}{l}\text { Post-Cleansing } \\
8 \text { hours }\end{array}$} & Dentural & 1.12110 & .01144 & \multirow[t]{2}{*}{.040} \\
\hline & & Fittty Dent & 1.12080 & .00483 & \\
\hline \multirow[t]{8}{*}{ Paan } & \multirow[t]{2}{*}{ Pre-stain } & Dentural & 1.05470 & .00508 & \multirow[t]{2}{*}{.721} \\
\hline & & Fitty Dent & 1.05380 & .00596 & \\
\hline & \multirow[t]{2}{*}{ Post-stain } & Dentural & 1.27280 & .00777 & \multirow[t]{2}{*}{.544} \\
\hline & & Fitty Dent & 1.27080 & .00665 & \\
\hline & \multirow{2}{*}{$\begin{array}{l}\text { Post-Cleansing } \\
15 \text { minutes }\end{array}$} & Dentural & 1.13820 & .00647 & \multirow[t]{2}{*}{.000} \\
\hline & & Fitty Dent & 1.11900 & .00579 & \\
\hline & \multirow{2}{*}{$\begin{array}{l}\text { Post-Cleansing } \\
8 \text { hours }\end{array}$} & Dentural & 1.13710 & .00456 & \multirow[t]{2}{*}{.000} \\
\hline & & Fitty Dent & 1.11900 & .00380 & \\
\hline
\end{tabular}

Table 3: Optical density following staining and cleansing in high-impact denture bases

\begin{tabular}{|c|c|c|c|c|c|}
\hline Type of stain & Time of measurement & Denture cleanser & Mean optical density ( $($ max) & Standard deviation (SD) & $p$-value \\
\hline \multirow[t]{8}{*}{ Tea } & \multirow[t]{2}{*}{ Pre-stain } & Dentural & 1.00430 & .04041 & \multirow[t]{2}{*}{.408} \\
\hline & & Fitty Dent & 1.01680 & .02267 & \\
\hline & \multirow[t]{2}{*}{ Post-stain } & Dentural & 1.23800 & .00982 & \multirow[t]{2}{*}{.700} \\
\hline & & Fitty Dent & 1.23640 & .00842 & \\
\hline & \multirow{2}{*}{$\begin{array}{l}\text { Post-Cleansing } \\
15 \text { minutes }\end{array}$} & Dentural & 1.16390 & .00390 & \multirow[t]{2}{*}{.000} \\
\hline & & Fitty Dent & 1.13910 & .00723 & \\
\hline & \multirow{2}{*}{$\begin{array}{l}\text { Post-Cleansing } \\
8 \text { hours }\end{array}$} & Dentural & 1.13690 & .00370 & \multirow[t]{2}{*}{.000} \\
\hline & & Fitty Dent & 1.12050 & .00331 & \\
\hline \multirow[t]{8}{*}{ Paan } & \multirow[t]{2}{*}{ Pre-stain } & Dentural & 1.02230 & .01615 & \multirow[t]{2}{*}{.587} \\
\hline & & Fitty Dent & 1.01620 & .03071 & \\
\hline & \multirow[t]{2}{*}{ Post-stain } & Dentural & 1.27720 & .00616 & \multirow[t]{2}{*}{.350} \\
\hline & & Fitty Dent & 1.27430 & .00730 & \\
\hline & \multirow{2}{*}{$\begin{array}{l}\text { Post-Cleansing } \\
15 \text { minute }\end{array}$} & Dentural & 1.20240 & .00508 & \multirow[t]{2}{*}{.000} \\
\hline & & Fitty Dent & 1.17160 & .00490 & \\
\hline & \multirow{2}{*}{$\begin{array}{l}\text { Post-Cleansing } \\
8 \text { hours }\end{array}$} & Dentural & 1.16220 & .00516 & \multirow[t]{2}{*}{.000} \\
\hline & & Fitty Dent & 1.13940 & .00306 & \\
\hline
\end{tabular}

acrylic resin denture bases and on the teeth are assumed to be caused by the same mechanisms and substances that cause deposits on natural teeth, of which salivary calculus and tobacco stains are the most common and most difficult to remove. ${ }^{9}$ The calcareous deposits consist of inorganic and organic portions and will vary from person to person due to difference in the composition of saliva. The organic portions are responsible for bonding the deposit to artificial surfaces. These organic portions contain protein to the extent of approximately 15 to $30 \%$ of total deposit. Unsaturated fatty acids are deposited secondarily on surfaces and contribute to plaque adhesiveness. ${ }^{6}$

Exogenous stains from dietary products accumulate on the denture in spite of all attempts to produce a selfcleansing design of dentures. ${ }^{3}$ Additionally, a denture is exposed to multiple staining solutions without any intermediate cleansing intervals in a day.

In India, tea is the most common beverage consumed (both in rural and urban population), while paan chewing is very common in rural India, and these staining agents were selected for the present study. ${ }^{3,10}$ Reasons for staining in the denture due to these stains are varied. Studies have suggested that the combination of dietary chromogens contained in tea and coffee can cause surface precipitation reaction leading to surface discoloration of the resin without the formation of metal sulfides. ${ }^{11}$ Comparing the staining potential of coffee, tea, and grape juice, Gispin and Caputo concluded that acidity favors staining and grape juice being more acidic caused increased staining of resin. ${ }^{12}$ 
Evaluation of Destaining Property of Denture Cleansers on Heat-cured Denture Base Resins

Table 4: Comparison of the performance of dental cleansers postcleansing 8 hours and following brushing

\begin{tabular}{|c|c|c|c|c|c|c|}
\hline $\begin{array}{l}\text { Type of denture } \\
\text { base }\end{array}$ & $\begin{array}{l}\text { Type of } \\
\text { Stain }\end{array}$ & $\begin{array}{l}\text { Time of } \\
\text { measurement }\end{array}$ & $\begin{array}{l}\text { Denture } \\
\text { cleanser }\end{array}$ & $\begin{array}{l}\text { Mean optical } \\
\text { density }(\lambda \text { max })\end{array}$ & $\begin{array}{l}\text { Standard } \\
\text { deviation (SD) }\end{array}$ & $p$-value \\
\hline & Tea & 8 hours & Dentural & 1.1211 & 0.01144 & 0.9792 \\
\hline \multirow[t]{8}{*}{ Conventional } & & Brushing & Dentural & 1.1195 & 0.01004 & \\
\hline & & 8 hours & Fitty Dent & 1.1208 & 0.00483 & 0.708 \\
\hline & & Brushing & Fitty Dent & 1.1293 & 0.03214 & \\
\hline & Paan & 8 hours & Dentural & 1.119 & 0.0038 & 0.915 \\
\hline & & Brushing & Dentural & 1.1181 & 0.00314 & \\
\hline & & 8 hours & Fitty Dent & 1.1371 & 0.00456 & 0.968 \\
\hline & & Brushing & Fitty Dent & 1.1359 & 0.0047 & \\
\hline & Tea & 8 hours & Dentural & 1.1205 & 0.00331 & 0.971 \\
\hline \multirow[t]{7}{*}{ High Impact } & & Brushing & Dentural & 1.1196 & 0.00313 & \\
\hline & & 8 hours & Fitty Dent & 1.1369 & 0.0037 & 0.968 \\
\hline & & Brushing & Fitty Dent & 1.1357 & 0.00386 & \\
\hline & Paan & 8 hours & Dentural & 1.1394 & 0.00306 & 0.971 \\
\hline & & Brushing & Dentural & 1.1381 & 0.00292 & \\
\hline & & 8 hours & Fitty Dent & 1.1622 & 0.00516 & 0.968 \\
\hline & & Brushing & Fitty Dent & 1.1609 & 0.0054 & \\
\hline
\end{tabular}

In the present study, a comparison of the staining quality of both the stains was done. It was found that paan stain produced more staining on both types of denture bases. The stains used (tea and paan) were water soluble. The PMMA denture base resins were hydrophilic that attracted water-soluble substances on the surface and staining, which occurs as a result of electrostatic charges. The presence of tobacco in the pan solution and the effect of tannic acid in the tea produced such staining. ${ }^{10}$ The $\mathrm{pH}$ of the staining solutions was measured, which showed paan to be more acidic with a $\mathrm{pH}$ of 4.06 in comparison to tea having a $\mathrm{pH}$ of 5.60. Thus, the increased staining property by paan can be attributed to its acidic nature, showing high affinity for acrylic resins.

A continued neglect of home care and/or lack of suitable cleansing results in accumulation of these undesirable substances on the surface of dentures. Methods of cleaning dentures could be mechanical cleansers, chemical cleansers, or a combination of the two. For effective mechanical cleansing, a reasonable amount of manual dexterity is needed for the patient. This may be lacking in the elderly. Immersion-type chemical cleansers are more popular among geriatric patients. They are classified as alkaline peroxides (percarbonate/perborate), alkaline hypochlorites, dilute organic or inorganic acids, disinfectants, and enzymes. ${ }^{13}$ Solutions easily reach all areas of the denture and result in complete cleaning. It also prevents denture abrasion and minimizes damage from mishandling of the denture.

Commercially available chemical cleansers are commonly distributed as tablets or powders, which upon dissolution in warm water chemically removes stain and deposits. The cleaning process generally takes 5 to 30 minutes; however, overnight soaking is commonly recommended. ${ }^{14,15}$

This study was carried out to compare the stain removal efficacy of two immersion-type cleansers, namely Dentural (sodium hypochlorite) and Fitty Dent (sodium perborate). Sodium hypochlorite is available only as aqueous solutions, which are usually prepared by adding chlorine to caustic soda. They act directly on the organic matrix of plaque, causing dissolution of the polymer structure. ${ }^{13}$ Hypochlorites can transform chromophores, thus accounting for the apparent ability of bleaches to remove the stain. They disinfect and deodorize dentures. Hypochlorites cause corrosion of metallic prosthetic appliance frameworks and pins of anterior porcelain teeth. They must be handled carefully to avoid damage to clothing and fabrics because of bleaching. Sodium perborate is available as powder and tablets. This is an oxygen-generating compound. It is responsible in large part for the bubbling action of denture cleansers, which exert a mechanical cleaning and antimicrobial effect. It is also an oxidizing agent and a weak bleaching agent. They form alkaline solutions of hydrogen peroxide when dissolved in water. They act primarily to break down, dissolve, and float away organic deposits. They accomplish this by the oxidation of organic compounds, corrosive alkalinity, and effervescence. They can be safely used on all metallic prosthetic appliances.

The evaluation of the denture cleansers was done on two types of denture base materials (DPI conventional, 
DPI high impact). Methodology was based on the study by Jagger et al. ${ }^{10}$

Several methods are available for assessing the color changes in the resin. Photographic method, ${ }^{16,17}$ fluorescence analysis, ${ }^{18}$ colorimeter $^{19}$ and spectrophotometer ${ }^{20}$ are widely used. The UV-VIS spectrophotometer used for the study consists of two instruments, namely spectrometer for producing light of any selected color/wavelength and a photometer for measuring the intensity of light. The instruments are arranged so that the substance in the cuvette can be placed between the spectrometer beam and the photometer. The photometer delivers the voltage signal to a display device, normally galvanometer. The signal changes as the amount of light absorbed by the material changes. The development of color is linked to the concentration of the substance, and the concentration can be measured by determining the extent of absorption of appropriate wavelength. This is done by Beer-Lambert law.

Comparing the two types of denture base materials with respect to staining potential, it is observed that at poststain stage, the mean value of optical density for the high-impact denture base material is higher than the conventional denture base material (Table 1). The values were obtained irrespective of the stains used in the study. The results showed that high-impact resin showed more stain formation compared with conventional denture base resin. This difference is statistically significant. Comparisons of the denture base materials at the postcleansing stages ( 15 minutes, 8 hours, and postbrushing) were also done. Statistically significant results were observed at all postcleansing phases.

Jagger et al. ${ }^{10}$ in their study of the effectiveness of denture cleansers on tea stain removal from PMMA resin concluded that irregularities and porosities present on the denture surface played a major role in retaining stain and microbial plaque. The mode of plaque attachment and stain buildup may be related to the roughness and porosity of the surface. These surface defects may favor the initial formation of plaque by protecting the organisms from dislodgement and could make the complete removal of plaque and stain difficult. In high-impact resins, reinforcing fibers including veined fibers are incorporated to improve the strength. These reinforcing fibers impart difficulty in finishing and polishing, and the surface shows more microscopic irregularities than conventional resins.

The extent of staining depends upon the contact angle and wettability of the resin. Contact angle measurements showed high-impact resin having low contact angle compared with conventional resin. Thus, high-impact resin is more wettable, having a greater affinity for stains that are hydrophilic in nature. The contact angle measurement of stained acrylic strips showed decreased contact angle measurement for paan-stained specimens than for teastained specimens, attributing to the increased staining observed with paan solution. The staining reduced the contact angle of the resin, making it more hydrophilic and consequently increasing the staining potential of the resin.

Among the two types of denture cleansers, it was found that for conventional denture base resin, for tea stain at postcleansing 15 minutes and postcleansing 8 hours, the values obtained for Dentural is higher than the values for Fitty Dent (Table 2). For paan stain in the same material at postcleansing 15 minutes and postcleansing 8 hours, a similar result is obtained (Table 2).

In the high-impact denture base resin, for tea stain as well as for paan stain, the mean value for postcleaning 15 minutes and postcleaning 8 hours for Dentural is higher than that obtained for Fitty Dent (Table 3).

Alkaline substances most frequently employed in denture cleansers are the phosphates, carbonates, and silicates. Only caustic alkalinity, or that alkali over $\mathrm{pH}$ of 8.5 , is considered available for cleaning purposes. Chemically, it is probable that the hydroxyl ions furnished by these alkalies are attracted to the surface being cleaned and neutralize the electrostatic forces between the surface and the foreign material. This allows the debris to become detached and migrate into the bulk of the solution. The penetration of these ions is aided by the wetting action of a surface-active material, and consequently, nearly all denture cleansers contain a small quantity of a synthetic detergent. The alkalies also exert some chemical action on the fatty and protein debris by saponification and hydrolysis. The $\mathrm{pH}$ of both the cleansers was measured, and it is found that $\mathrm{pH}$ of Dentural is 11.5 and $\mathrm{pH}$ of Fitty Dent is 9.8. Since alkalinity is a measure of the efficiency of the cleanser, Dentural, which contains sodium hypochlorite, is a better cleanser than Fitty Dent, which contains sodium perborate.

The results were analyzed and it is found that sodium hypochlorite removed stains more effectively than sodium perborate both at 15 -minute and 8-hour stages, the 8-hour cleansing period being better. This is found to be statistically significant for both stains on both the denture bases (Table 3).

The postcleansing 8-hour stage was followed by brushing and the results were analyzed (Table 4). It is observed that the brushing reduced the stain in all the samples. But the result is not statistically significant.

The results of the present study were in accordance with the findings of Jagger et $\mathrm{al}^{10}$ where sodium hypochlorite denture cleanser was used and was found to be a better cleanser than Boots Denture Cleaning Powder. In another study by Hutchins and Parker, ${ }^{21}$ they concluded that effervescent tablets containing alkaline peroxides are not effective in removal of denture surface deposits. 
Even though hypochlorite cleansers are effective in stain removal, their bleaching effect should be considered. $^{22}$ In the present study, the bleaching effect was not evaluated, and is a consideration for future research.

\section{CONCLUSION}

It was found that the high-impact denture base resin stained more than the conventional denture base resin for both type of stains with statistical significance. Of the stains studied, paan stain was found to have maximum staining potential. The cleansers studied were effective in removal of stains from the denture surface. Immersion of the specimens in 15 minutes and 8 hours in the cleansers significantly reduced the staining, and 8-hour immersion time is better. Dentural is a better cleanser than Fitty Dent for all the postcleansing stages in both the denture base resins. There was no statistically significant difference between the 8-hour immersion period in the cleansers and the brushing that followed.

\section{REFERENCES}

1. Bergman B, Carlsson GE. Clinical long-term study of complete denture wearers. J Prosthet Dent 1985 Jan;53(1):56-61.

2. Augsburger RH, Elahi JM. Evaluation of seven proprietary denture cleansers. J Prosthet Dent 1982 Apr;47(4):356-359.

3. Thakral GK, Tandon BK, Agarwal NK. An evaluation of denture cleansers manufactured in India. J Indian Dent Assoc 1985 Mar;57(3):107-111.

4. Alam M, Jagger R, Vowles R, Moran J. Comparative stain removal properties of four commercially available denture cleaning products: an in vitro study. Int J Dent Hyg 2011 Feb;9(1):37-42.

5. American Dental Association. Guide to dental materials and devices. 6th ed. Chicago: American Dental Association; 1974-1975. p. 152-153.

6. Budtz-Jørgensen E. Materials and methods for cleaning dentures. J Prosthet Dent 1979 Dec;42(6):619-623.

7. Love WD, Goska FA, Mixson RJ. The etiology of mucosal inflammation associated with dentures. J Prosthet Dent 1967 Dec;18(6):515-527.
8. Anthony DH, Gibbons P. The nature and behavior of denture cleansers. J Prosthet Dent 1958 Sep-Oct;8(5):796-810.

9. Nicholson RJ, Stark MM, Scott HE Jr. Calculus and stain removal from acrylic resin dentures. J Prosthet Dent 1968 Oct;20(4):326-329.

10. Jagger DC, Al-Akhazam L, Harrison A, Rees JS. The effectiveness of seven denture cleansers on tea stain removal from PMMA acrylic resin. Int J Prosthodont 2002 NovDec;15(6):549-552.

11. Scotti R, Mascellani SC, Forniti F. The in vitro color stability of acrylic resins for provisional restorations. Int J Prosthodont 1997 Mar-Apr;10(2):164-168.

12. Gispin BJ, Caputo AA. Color stability of temporary restorative materials. J Prosthet Dent 1979 Jul;42(1):27-33.

13. Abere DJ. Post-placement care of complete and removable partial dentures. Dent Clin North Am 1979 Jan;23(1):143-151.

14. Neill DJ. A study of materials and methods employed in cleaning dentures. Br Dent J 1968 Feb;124(3):107-115.

15. Peracini A, de Andrade IM, Paranhos HFO, da Silva CHL, de Souza RF. Behaviors and hygiene habits of complete denture wearers. Braz Dent J 2010 Jun;21(3):247-252.

16. Sato S, Cavalcante MRS, Orsi IA, Paranhos HFO, Zaniquelli O. Assessment of flexural strength and color alteration of heatpolymerized acrylic resins after simulated use of denture cleansers. Braz Dent J 2005 May/Aug;16(2):124-128.

17. Wozniak WT, Muller TP, Silverman R, Moser JB. Photographic assessment of colour changes in cold and heat-cure resins. J Oral Rehabil 1981 Jul;8(4):333-339.

18. Adeyemi AA, Jarad F, Pender N, Higham SM. Assessing the efficacy of denture cleaners with quantitative light-induced fluorescence (QLF). Eur J Prosthodont Restor Dent 2007 Dec;15(4):165-170.

19. Hong G, Murata H, Li Y, Sadamori S, Hamada T. Influence of denture cleansers on the color stability of three types of denture base acrylic resin. J Prosthet Dent 2009 Mar;101(3): 205-213.

20. Hersek N, Canay S, Uzun G, Yildiz P. Color stability of denture base acrylic resins in three food colorants. J Prosthet Dent 1999 Apr;81(4):375-379.

21. Hutchins DW, Parker WA. A clinical evaluation of the ability of denture cleansing solution to remove dental plaque from prosthetic devices. NY State Dent J 1973 Jun-Jul;39(6):363-367.

22. Jagger DC, Harrison A. Denture cleansing - the best approach. Br Dent J 1995 Jun;178(11):413-417. 